\title{
Fetal awareness and fetal pain: the Emperor's new clothes
}

\author{
Martin Ward Platt
}

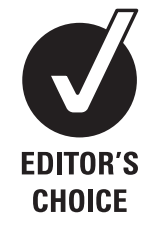

In June 2010, the Royal College of Obstetricians and Gynaecologists (RCOG) published Fetal Awareness - Review ofResearchandRecommendations for Practice. ${ }^{1}$ The College's purpose was to update their 1997 publication ${ }^{2}$ in the light of more recent evidence, and also to provide "information for women and parents". Although they use the term 'fetal awareness', both publications predominantly address the issue of whether or not the fetus feels pain, and at what gestational ages this might be so. The conclusions of the summary of the evidence review are set out in box 1 , and the main practice points derived from this are set out in box 2 . The report caused a considerable furore in the media, where it was widely portrayed as being a political rather than a scientific document that aimed to shore up the pre-existing position of the RCOG rather than to take a dispassionate view of the scientific evidence. I do not intend to take on the political dimension, but it is worth re-examining some of the science.

The core of the scientific argument in the document can be summarised thus:

- The fetus is rendered unconscious during intrauterine life by endogenous substances.

- And the fetus at under 24 weeks does not have the neuroanatomical apparatus that would allow pain perception at a cortical level.

- Therefore the fetus is neither aware, nor can feel pain, under 24 weeks.

Let us first take the issue of awareness, bearing in mind that the report states: "There is increasing evidence that the fetus never experiences a state of true wakefulness in utero and is kept, by the presence of its chemical environment, in a continuous sleep-like unconsciousness or sedation". This is a far-reaching statement, since it implies that any research on the cognitive capacity of the human

Correspondence to Dr Martin Ward Platt, Newcastle Neonatal Service, Ward 35, Royal Victoria Infirmary, Queen Victoria Road, Newcastle upon Tyne NE1 4LP, UK; m.p.ward-platt@ncl.ac.uk fetus is impossible. In addition, the reason that the issue of awareness assumes such importance in the report is because if you can argue yourself into the position of refuting the possibility of awareness while in utero, you don't need to take into account the measurable experiences of infants who, having been born at the gestational ages under discussion, can be observed much more rigorously than the fetus. By deploying the argument that the fetus is in a different conscious state to the newborn, anything observed in the baby at an equivalent gestation can be dismissed as irrelevant to the discussion.

So, what is the evidence that the human fetus lacks 'awareness'? In a word, there is none. The only evidence, including the bit about the chemical environment, is in sheep and one or two other experimental animals. I have looked at the references in the report, and the references in the references, and when I finally got back to the primary literature I found no evidence for the contention that human fetuses lack awareness, or exist in some different conscious state, beyond the unwarranted extrapolation from sheep.

In contradiction to the notion of the 'unaware' fetus, the everyday experience of pregnancy - the felt behaviours and responses of the unborn baby, especially to sound - as well as much primary research literature on the human fetus, contains strong evidence for an opposite view. There is an extensive literature, in humans, on fetal sleep and wakefulness, ${ }^{3}$ fetal motility, ${ }^{4}$ fetal memory, ${ }^{5}$ fetal hearing, ${ }^{6}$ fetal breathing and its control ${ }^{7}$ and fetal behaviour ${ }^{8}$ - and these are just examples that scratch the surface. None of this work is easily reconciled with the notion of a permanently unconscious human fetus. The third point in box 1 is simply not true.

Once the notion of the 'unaware' fetus is robustly dismissed, the observations of parents, nurses and neonatal doctors, on newborn but extremely premature babies, together with rigorous research, become relevant. We know from our everyday experience that there is no substantial difference between the behaviours and responses of babies at 23, 24 and 25 weeks. Over the last 20 or more years, researchers have accumulated good observational, experimental and pathophysiological reasons to consider that babies at these gestations do feel pain, that they benefit from analgesia, and that pain experiences in early life cast neurophysiological and behavioural

\section{Conclusions of the summary of evidence}

- The lack of cortical connections before 24 weeks implies that pain is not possible until after 24 weeks.

- Even after 24 weeks, there is continuing development and elaboration of intracortical networks.

- Furthermore, there is good evidence that the fetus is sedated by the physical environment of the womb and usually does not awaken before birth.

\section{Main practice points}

- The case for administering analgesia before an invasive procedure (in addition to maternal general anaesthesia) after 24 weeks when the neuroanatomical connections are in place, needs to be considered together with the practicalities and risks of administration of fetal analgesia in continuing pregnancies and the uncertainties over long-term effects.

- Evidence that analgesia confers any benefit on the fetus at any gestation is lacking but should be a focus of future research that will need to include medium and longer term as well as immediate outcomes.

- However, the need for maternal sedation before fetal interventions such as transfusion or feticide is still recognised, as it provides both maternal and procedural benefits. 
shadows far down childhood. ${ }^{9}$ Equally importantly, babies have a right to receive humane treatment. We work from an ethical imperative that even though these babies cannot verbalise their experiences, and cannot remember them in any way comparable to a child or adult, they should not be subject to pain or distress if we can possibly prevent or treat it. From this argument, there is no reason not to treat the 23-week fetus like a 24- or 25 -week fetus, just as we do for babies.

Just in case we might have had some difficulty with the 'awareness' argument, the report dismisses observed neonatal pain experiences thus: "Extremely preterm infants of 24-30 weeks of gestation show the same motor responses to a noxious heel lance (required for clinical blood sampling) even when there is severe damage of the pathways connecting the spinal cord and brainstem to higher brain centres". The argument here is that since the behaviour occurs even in the absence of a cerebral cortex, we can't know whether it is experienced cortically in babies who do have a cortex. Simplistically this is true, but it does not invalidate the precautionary principle of prevention and treatment of pain in case it is being experienced, which is an ethical rather than a scientific argument, nor does it affect the evidence in relation to the long term neurobiological effects of pain experiences in preterm babies. The fact that the stress and pain reflex response arcs act at multiple levels (spinal cord, brainstem nuclei, thalamus and cortex) in no way refutes the concern that where a cortex is present, pain may be experienced.

One notices statements in the report such as: "Interpretation of existing data indicates that cortical processing of pain perception, and therefore the ability of the fetus to feel pain, cannot occur before 24 weeks of gestation". We could rewrite this as in theory they can't feel pain, therefore they don't'. It is the substitution of wishful thinking for empirical enquiry. It reminds me of my days as a medical student when I was taught that once the periosteum was anaesthetised, bone marrow aspiration was painless because there were no nerve endings in the bone. As soon as I came to perform bone marrow aspiration I realised that, whether there were supposed to be nerve endings or not, the procedure caused deep bone pain. So: should we deny patients' real experiences on entirely theoretical grounds, or accept them and look harder for the underlying cause? We now know that bone is richly innervated, but older techniques of bone histology were unable to demonstrate the fibres. ${ }^{10}$ Analogously, we need to spend more time understanding the fetus from the point of view of pregnant women, and seek explanations for the observations. Instead, it seems that this report constructs a theoretical viewpoint and then tries to squeeze the contrary observations of the real world into it - just like the naked emperor in Hans Anderson's story, who in his vanity, and because enough courtiers agreed with him, considered himself clothed. ${ }^{11}$

In contrast to the scientific position of the report, the recommendations for practice are a model of common sense. In the noise of the media concern about the interpretation of the science, this important point was overlooked. So it is a pity that the first two question-and-answers in the section for women and parents consist of didactic statements about the inability of the fetus to feel pain that in my view cannot be supported from the literature.

Where I cannot be critical is in relation to the report's call for more research. In preparing this editorial I noticed that there seems to be no scientific literature on fetal behaviours that uses the maternal experience of quickening, or other aspects of fetal responsiveness, as its basis. This is a huge methodological gap, because although ultrasound studies are both detailed and objective, they only ever take place in artificial environments and can only be undertaken for relatively short periods of time. We need ambulatory fetal activity monitoring so that the circadian and ultradian patterns of fetal behaviour in daily life can be delineated.
The second issue is that the literature on fetal behaviour, perception, organisation, movement and responses focuses largely on fetuses above 28 weeks of gestation, with a relative lack of studies on the fetus between 20 and 24 weeks. This results in too much reliance on neuroscience, too much reference to animal work, too much extrapolation from both of these and too little real-world human investigation on which to base a realistic view. No one would deny that there are important issues to be confronted, but a sensible debate needs a solid base of rigorous empirical enquiry. As it stands, the report is an emperor with no clothes. We need to dress him.

Competing interests The author supports the current UK legislation in relation to termination of pregnancy.

Provenance and peer review Commissioned; externally peer reviewed.

Accepted 5 January 2011

Published Online First 3 February 2011

Arch Dis Child Fetal Neonatal Ed 2011:96:F236-F237. doi:10.1136/adc.2010.195966

\section{REFERENCES}

1. Royal College of Obstetricians and Gynaecologists. Fetal Awareness - Review of Research and Recommendations for Practice. London: RCOG Press 2010.

2. Royal College of Obstetricians and Gynaecologists. Fetal Awareness: Report of a Working Party. London: RCOG Press 1997.

3. Mirmiran M, Maas YG, Ariagno RL. Development of fetal and neonatal sleep and circadian rhythms. Sleep Med Rev 2003;7:321-34.

4. de Vries JI, Fong BF. Normal fetal motility: an overview. Ultrasound Obstet Gynecol 2006;27:701-11.

5. Hepper PG. Memory in utero? Dev Med Child Neurol 1997;39:343-6.

6. Hepper PG, Shahidullah BS. Development of fetal hearing. Arch Dis Child 1994;71:F81-7.

7. Jansen $\mathbf{A H}$, Chernick V. Fetal breathing and development of control of breathing. J App/ Physiol 1991;70:1431-46.

8. Robles de Medinaa PG, Visser GH, Huizink AC, et al. Fetal behaviour does not differ between boys and girls. Early Hum Dev 2003;73:17-26.

9. Fitzgerald $\mathbf{M}$, Walker SM. Infant pain management: a developmental neurobiological approach. Nat Clin Pract Neurol 2009;5:35-50.

10. McCredie J. Nerves in bone: the silent partners. Skeletal Radiol 2007;36:473-5.

11. Anderson HC. Anderson's Fairy Tales. Ware: Wordsworth Editions 1993 